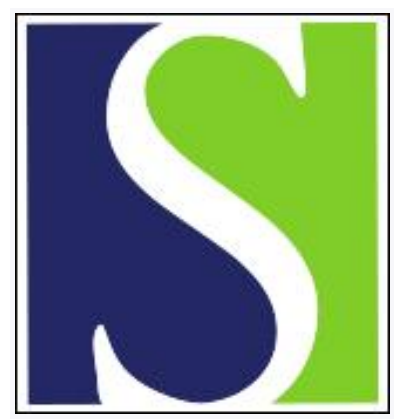

Scand J Work Environ Health 2010;36(6):499-508

https://doi.org/10.5271/sjweh.3088

Published online: 13 Sep 2010, Issue date: Nov 2010

Reduced lung cancer mortality and exposure to synthetic fluids and biocide in the auto manufacturing industry

by Mehta AJ, Malloy EJ, Applebaum KM, Schwartz J, Christiani DC, Eisen EA

Affiliation: Swiss Tropical and Public Health Institute, Socinstrasse 57, Room S302, Switzerland. amar.mehta@unibas.ch

Refers to the following texts of the Journal: 2001;27(4):240-249 1990;16(2):113-120

The following articles refer to this text: 2012;38(1):78-83;

2020;46(5):525-532

Key terms: auto manufacturing industry; biocide; cohort study; endotoxin; exposure; lung cancer; lung cancer mortality; metalworking fluid; mortality; occupational epidemiology; retrospective cohort study; synthetic biocide; synthetic fluid

This article in PubMed: www.ncbi.nlm.nih.gov/pubmed/20835688 


\title{
Reduced lung cancer mortality and exposure to synthetic fluids and biocide in the auto manufacturing industry
}

\author{
by Amar J Mehta, $S c D$, MPH, ${ }^{1}$ Elizabeth J Malloy, PhD, MA, ${ }^{2}$ Katie M Applebaum ScD, MSPH, ${ }^{1,3}$ Joel \\ Schwartz, PhD, ${ }^{4}$ David C Christiani, MD, MSc, MPH, ${ }^{1}$ Ellen A Eisen, ScD, MSc ${ }^{1,5}$
}

\begin{abstract}
Mehta AJ, Malloy EJ, Applebaum KM, Schwartz J, Christiani DC, Eisen EA. Reduced lung cancer mortality and exposure to synthetic fluids and biocide in the auto manufacturing industry. Scand $J$ Work Environ Health. 2010;36(6):499-508.
\end{abstract}

Objectives Water-based soluble and synthetic metalworking fluids (MWF) used in auto manufacturing may be contaminated by endotoxin from Gram-negative bacteria, a possible anticarcinogen via increased immunosurveillance. The effectiveness of biocide, generally added to limit bacterial growth is unknown. We investigated whether an inverse relationship between lung cancer and synthetic MWF and biocide - as surrogates of endotoxin exposure - persisted in an extended follow-up of autoworkers.

Methods A nested case-control analysis was performed within a retrospective cohort study of 46399 auto manufacturing workers. Follow-up began in 1941 and was extended from 1985-1995. Mortality rate ratios (MRR) were estimated in Cox regression models for lung cancer as discrete and smoothed functions of cumulative exposure to synthetic MWF $\left(\mathrm{mg} / \mathrm{m}^{3}\right.$ per year) and years exposed to biocide with both synthetic and soluble MWF. The analysis was also restricted to the subcohort hired on or after 1941 and stratified by follow-up period.

Results The splines suggested a non-linear inverse exposure-response for lung cancer mortality with increasing endotoxin exposure. Overall, the greatest reduction in mortality was observed among those with the highest exposure [MRR $0.63,95 \%$ confidence interval $(95 \% \mathrm{CI}) 0.39-0.98$ ] at the $99^{\text {th }}$ percentile of exposure $\left(15.8 \mathrm{mg} / \mathrm{m}^{3}\right.$ per year). Evidence for an inverse effect was limited to the earlier follow-up period. Effect modification by biocide was marginally significant $(\mathrm{P}=0.07)$; the protective effect of synthetic MWF was observed only for those who were co-exposed.

Conclusions The protective effect of synthetic MWF against lung cancer mortality persisted through the extended period of follow-up, although attenuated, and was observed only among workers with co-exposure to biocide and synthetic MWF.

Key terms endotoxin; metalworking fluid; occupational epidemiology; retrospective cohort study.

Endotoxin, commonly referred to as lipopolysaccharide (LPS), is a component of the outer membrane of the cell wall of Gram-negative bacteria and is generally released from bacterial lysis (1). Although endotoxin is ubiquitous in the airborne environment, high airborne endotoxin levels are observed in industrial environments where organic dusts are present (eg, swine barns, cotton mills, grain handling) or where environmental media that support bacterial growth are present [eg, water-based metalworking fluids (MWF) in auto manufacturing] (2). The non-malignant respiratory health effects of endotoxin are well documented in occupational epidemiologic studies of workers exposed to cotton and other organic dust (3-6). There is also limited evidence supporting the potential anticarcinogenic effects of endotoxin on lung cancer, most notably in studies of agricultural workers and workers in the cotton textile industry (7-12).

Early studies of cotton textile workers in the US and UK indicate a decrease in lung cancer mortality in proportion to increasing levels and duration of exposure to cotton dust (8-10). While early mortality studies lack quantitative measurements of endotoxin, a recent cohort

1 Environmental and Occupational Medicine and Epidemiology Program, Department of Environmental Health, Harvard School of Public Health, Boston, MA, USA

2 Department of Mathematics and Statistics, American University, Washington, DC, USA

3 Department of Epidemiology, Boston University School of Public Health, Boston, MA, USA

4 Exposure, Epidemiology, and Risk Program, Department of Environmental Health, Harvard School of Public Health, Boston, MA, USA

5 Department of Environmental Health Sciences, University of California Berkeley School of Public Health, Berkeley, CA, USA

Correspondence to: Amar J Mehta, Swiss Tropical and Public Health Institute, Socinstrasse 57, Room S302, Switzerland. [E-mail: amar.mehta@unibas.ch] 
study of female cotton textile workers based in Shanghai identified a quantitative inverse exposure-response relationship between endotoxin and lung cancer incidence (11). Although specific mechanisms have not been fully elucidated, the observed protective effect against lung cancer has been attributed to endotoxin, released by Gram-negative bacteria proliferating on cotton dust, possibly mediated by the innate and acquired immune responses to endotoxin (13-15). There are few studies outside of the cotton textile and dairy farming industries that have investigated the association between lung cancer and endotoxin, so whether similar trends in lung cancer mortality are observed in other occupational cohorts exposed to endotoxin remains an important unanswered question.

MWF provide another media through which occupational exposure to endotoxin can occur. More than 1.2 million workers in many industrial settings in the United States are exposed to MWF, which are used for cooling and lubrication in metalworking and machining operations (16). The largest industry where this exposure is common is automobile manufacturing. MWF are typically classified as oil- (straight mineral oil) or water-based (soluble oil, semi-synthetic, and synthetic MWF). Water-based MWF contain chemical components that are conducive to microbial growth (17). Earlier exposure assessment studies of industrial environments with MWF also reported a positive correlation between water-based MWF particulate mass and airborne endotoxin (18-20). A more recent study, which was performed under controlled conditions in a laboratory and under routine operations in the field, observed that the concentration of airborne endotoxin in the presence of synthetic MWF increased with decreasing aerodynamic size of MWF particulate (21). The same study reported that the mean endotoxin in airborne particulate mass ranged from $11.6-126.7 \mathrm{EU} / \mathrm{m}^{3}$, where semi-synthetic MWF were in use, and from 3.4-33 $000 \mathrm{EU} / \mathrm{m}^{3}$ where synthetic MWF were in use (21). The upper end of these endotoxin ranges are relatively high compared to the "no observed effect levels" (NOEL) that have been proposed for non-malignant respiratory health effects from acute and chronic exposure to endotoxin including shortness of breath, dyspnea, chronic bronchitis, airflow obstruction, and accelerated decline in lung function $(22,23)$.

The deterioration of water-based MWF caused by bacterial growth generates a foul odor, and anti-microbial agents known as biocides are routinely added to suppress bacterial growth. However, numerous studies examining the effectiveness of biocides in bulk samples of water-based MWF suggest that successful long-term reduction of bacterial (24-26) and endotoxin (26) contamination is debatable.

A previous analysis of lung cancer mortality in a nested case-control study, based in the United Auto- worker General Motors (UAW-GM) cohort, found statistically significant inverse associations between lung cancer and cumulative exposure to synthetic MWF [relative risk (RR) for $>1.85 \mathrm{mg} / \mathrm{m}^{3}$ per year was 0.6 , $95 \%$ confidence interval $(95 \% \mathrm{CI}) 0.4-0.8]$ and years exposed to biocide (RR for $>8.5$ years was $0.5,95 \% \mathrm{CI}$ 0.3-0.9) (27). Interestingly, no association was observed between lung cancer and the oil-based MWF, which do not support microbial growth.

Since this earlier publication, the number of lung cancer deaths in the UAW-GM cohort has almost doubled with ten years of additional follow-up. With this increased power, we investigated whether the protective effects of synthetic MWF and biocide, interpreted as surrogate measures of endotoxin exposure, were still present. We also examined new biocide exposure metrics that distinguished whether the exposure occurred in synthetic versus soluble MWF exposed jobs.

\section{Methods}

\section{Study design and population}

Descriptions of the UAW-GM autoworkers cohort and exposure data have been discussed in detail previously $(16,28-30)$. The study design for this lung cancer analysis is a nested case-control analysis within the retrospective cohort consisting of 46399 autoworkers from three manufacturing plants (Plants I, II, and III) in Michigan. Hourly employees who had ever worked at least three years prior to 1 January 1985 were included in the cohort and the period of follow-up was from 1 January 1941 to 31 December 1984, later extended to 31 December 1994. Participants with $>50 \%$ of their work history missing were excluded $(\mathrm{N}=2215)$ and were not eligible for sampling in this analysis. Demographic and job history information was collected from work records.

\section{Outcome assessment}

To determine the underlying cause of death as recorded on the death certificate, plant, union, and state vital statistics office records were used, as well as the National Death Index Plus. International Classification of Diseases, ninth edition (ICD-9) was used to classify lung cancer mortality (ICD-9=162). A total of 1137 lung cancer deaths met these criteria.

\section{Exposure assessment}

The three plants in this study were selected to represent the full range of exposure to the major types of MWF: straight, soluble, semi-synthetic, and synthetic. Semi- 
synthetic MWF was combined with soluble MWF in this and all previous analyses of cancer outcomes in this cohort study. To summarize the exposure history of the plants in brief, Plant I used predominantly soluble and straight MWF while Plants II and III used all fluid types (28). Peak levels of exposure to synthetic MWF occurred during the early 1950s and mid-to-late 1960s in Plants II and III, respectively. Biocides were used predominantly in Plant II, beginning in the early 1950s, coinciding with the earliest introduction of synthetic MWF. Peak use of biocides occurred later in the 1980s, when exposure levels for synthetic MWF had been substantially controlled in Plant II (relative to the 1950s).

An extensive retrospective exposure assessment, based on historical company records and field surveys collected by the research team, was conducted to estimate past exposure levels to straight, soluble, semisynthetic, and synthetic MWF (16, 29, 30). Particulate mass concentration $\left(\mathrm{mg} / \mathrm{m}^{3}\right)$ for fluid type was measured by plant, department, operation, and size fraction, and the concentration was scaled relative to the time period of exposure. Industrial hygiene data collected from the field surveys showed that total mass and respirable particulate mass measurements were highly correlated $(r \geq 0.9)$ for all fluid types. Cumulative exposure $\left(\mathrm{mg} / \mathrm{m}^{3}\right.$ per year) to each MWF was derived as a time-weighted average from job-specific estimates of total particulate mass concentrations combined with personal work histories. Qualitative exposure to biocides was evaluated (yes/no) in each job determined by information ascertained from material data safety sheets. Using personal work histories, years of exposure to biocide with synthetic and soluble fluids were estimated for each subject.

\section{Nested case-control sampling}

Workers were eligible to serve as a control if they were alive at the age of case death. We randomly sampled $\leq 20$ controls per case matched by age at death. The nested case-control sample for analysis within the full cohort consisted of 1137 cases and 22740 control person-years (from 13002 distinct subjects).

\section{Incident hires subcohort}

A recent study of lung cancer mortality among Vermont granite workers found that inclusion of "prevalent hires" in the cohort (ie, workers hired before start of follow-up) induced a downward bias on the effect of silica dust on lung cancer mortality (31). To evaluate the influence of the prevalent hires in the present study, we repeated the analysis restricted to a subcohort of "incident hires" (ie, workers hired on or after the start of follow-up on 1 January 1941), thus the period of follow-up began on or after 1 January 1944. The nested case-control sample for analysis within the subcohort consisted of 837 cases and 16740 control-years (from 9870 distinct subjects).

\section{Statistical analysis}

Cox proportional hazards regression was used to estimate mortality rate ratios (MRR) and respective 95\% $\mathrm{CI}$ for lung cancer and exposure to biocide and specific MWF (R version 2.7). The Cox model was also extended to allow the baseline hazard and covariates to vary over time $t$ (age), which was used to define the risk sets. Each exposure metric was divided into five categories with the unexposed as the reference category, and the exposed were divided into quartiles based on the distribution of exposed cases. All models were adjusted for exposures to all other fluid types, as well as race [AfricanAmerican, unknown, and Caucasian (as reference)], gender (male as reference), plant [Plant II, Plant III, and Plant I (as reference)], calendar year of follow-up (continuous), and years since retirement (continuous, value of 0 was assigned for active employment). To evaluate MRR by time period of follow-up, the Cox models were also stratified by year of follow-up (1941-1984, and 1985-1994). The likelihood displacement statistic, which approximates how much of the log-likelihood would change after removal of an observation, was used to identify potentially influential observations.

To relax parametric assumptions regarding the shape of the exposure-response curve, a flexible smoothing approach was incorporated with a penalised spline function of exposure into the Cox models. For each exposure variable, the spline was retained if degrees of freedom (DF) selected by Akaike information criterion (AIC) was $>1.0$ and the non-linear term had $\mathrm{P}<0.10$ (32). Observations above the $99^{\text {th }}$ percentile of exposure were excluded in a sensitivity analysis.

We also evaluated if early exposures were more or less important than recent exposure in lung cancer risk by dividing cumulative exposure to each major fluid type into two time windows of exposure; $>$ or $<20$ years prior to event (for cases) or age at risk (for controls), which were mutually adjusted for in the model. To distinguish the effect of synthetic MWF from exposure to biocide, lung cancer was modeled as a function of cumulative exposure to synthetic MWF, in strata defined by "ever or never exposed" to biocide in synthetic MWF.

\section{Results}

Of the 1137 lung cancer deaths, approximately $73 \%$ were incident hires, those hired on or after the start of follow-up ( $\mathrm{N}=837)$. The distribution of demographic characteristics was similar between cases and controls 
within both the full cohort and incident hires subcohort, although cases were more likely to be male than female (table 1). The sample nested in the subcohort had a higher proportion of females, African-Americans, and cases that died while actively employed compared to the full cohort. Cumulative exposure to synthetic MWF, and years exposed to biocide with both synthetic and soluble MWF were all right-skewed distributions, but similar between cases and controls nested in both the full cohort and subcohort of incident hires. The mean exposures were slightly higher for the subcohort relative to the full cohort, consistent with the more recent introduction of the water-based MWF.

The models for lung cancer as a function of categorized exposures to synthetic MWF and biocide with both synthetic and soluble MWF are summarized in table 2.
Null associations were observed for synthetic MWF in the incident hires subcohort, but the strongest inverse risk was observed among workers in the highest quartile relative to unexposed workers. Similarly, null associations were also observed for years exposed to biocide with both synthetic and soluble MWF. There was little difference in MRR estimates between the subcohort and full cohort for any exposure metric (data not shown). There were no significant linear trends for each of the exposure variables (Chi-square test for trend $\mathrm{P}>0.20$ ) so we proceeded with nonparametric exposure-response models.

The penalized spline model of lung cancer for cumulative exposure to synthetic MWF is summarized in figure 1. A non-linear inverse exposure-response was observed in the incident hires subcohort $(\mathrm{DF}=2.2$, $\mathrm{P}=0.02)$ and the full cohort $(\mathrm{DF}=2.4, \mathrm{P}=0.02)$. Estimates

Table 1. Distribution of characteristics in cases and controls of lung cancer nested within the full cohort and incident hires subcohort in person-time. [M=Mean; SD=standard deviation; MWF=metalworking fluid; IQR=inter-quartile range.]

\begin{tabular}{|c|c|c|c|c|c|c|c|c|c|c|c|c|c|c|c|c|}
\hline & \multicolumn{8}{|c|}{ Full cohort } & \multicolumn{8}{|c|}{ Incident hires subcohort a } \\
\hline & \multicolumn{4}{|c|}{$\begin{array}{c}\text { Cases } \\
\text { Person-years }=1137\end{array}$} & \multicolumn{4}{|c|}{$\begin{array}{c}\text { Controls }{ }^{\mathrm{b}} \\
\text { Person-years }=22740\end{array}$} & \multicolumn{4}{|c|}{$\begin{array}{c}\text { Cases } \\
\text { Person-years=837 }\end{array}$} & \multicolumn{4}{|c|}{$\begin{array}{c}\text { Controls }{ }^{b} \\
\text { Person-years }=16740\end{array}$} \\
\hline & M & SD & $\mathrm{N}$ & $\%$ & M & SD & $\mathrm{N}$ & $\%$ & M & SD & $\mathrm{N}$ & $\%$ & $\mathrm{M}$ & SD & $\mathrm{N}$ & $\%$ \\
\hline $\begin{array}{l}\text { Age at start of } \\
\text { follow-up }\end{array}$ & 36.0 & 8.8 & & & 37.9 & 9.9 & & & 36.2 & 9.4 & & & 37.1 & 10.2 & & \\
\hline $\begin{array}{l}\text { Age at death } \\
\text { (or age at risk) }\end{array}$ & 65.0 & 10.3 & & & 65.0 & 10.3 & & & 63.3 & 9.9 & & & 63.3 & 9.9 & & \\
\hline $\begin{array}{l}\text { Duration of } \\
\text { follow-up (years) }\end{array}$ & 28.5 & 10.8 & & & 36.3 & 10.6 & & & 26.6 & 10.4 & & & 34.5 & 9.8 & & \\
\hline \multicolumn{17}{|l|}{ Race } \\
\hline Caucasian & & & 643 & 56.6 & & & 14851 & 65.3 & & & 373 & 44.6 & & & 8936 & 53.4 \\
\hline $\begin{array}{l}\text { African- } \\
\text { American }\end{array}$ & & & 140 & 12.3 & & & 2685 & 11.8 & & & 134 & 16.4 & & & 2737 & 16.4 \\
\hline Unknown & & & 354 & 31.1 & & & 5204 & 22.9 & & & 327 & 39.1 & & & 5067 & 30.3 \\
\hline Males & & & 1082 & 95.2 & & & 21000 & 92.4 & & & 782 & 93.4 & & & 14946 & 89.3 \\
\hline Year of hire & 1949 c & & & & $1947^{c}$ & & & & 1952 c & & & & $1952^{c}$ & & & \\
\hline $\begin{array}{l}\text { Employed at age } \\
\text { of death (or age } \\
\text { at risk) }\end{array}$ & & & 146 & 12.8 & & & 5924 & 26.1 & & & 113 & 13.5 & & & 5340 & 31.9 \\
\hline \multicolumn{17}{|l|}{ Plant } \\
\hline I & & & 534 & 47.0 & & & 11092 & 48.8 & & & 266 & 31.8 & & & 4765 & 28.5 \\
\hline II & & & 436 & 38.4 & & & 8045 & 35.4 & & & 418 & 49.9 & & & 8213 & 49.1 \\
\hline III & & & 167 & 14.7 & & & 3603 & 15.8 & & & 153 & 18.3 & & & 3762 & 22.5 \\
\hline $\begin{array}{l}\text { Cumulative } \\
\text { exposure to } \\
\text { synthetic MWF } \\
\text { (mg/m³ per year) }\end{array}$ & $0.7^{d}$ & 5.1 & & & $0.7^{d}$ & 4.0 & & & $0.9 \mathrm{e}$ & 6.0 & & & $1.0^{f}$ & 5.0 & & \\
\hline $\begin{array}{l}\text { Years exposed to } \\
\text { biocide with } \\
\text { synthetic MWF }\end{array}$ & $0.2^{d}$ & 1.1 & & & $0.3^{d}$ & 1.3 & & & $0.3^{d}$ & 1.2 & & & $0.4^{d}$ & 1.6 & & \\
\hline $\begin{array}{l}\text { Years exposed } \\
\text { to biocide with } \\
\text { soluble MWF }\end{array}$ & $0.1^{d}$ & 0.4 & & & $0.1^{d}$ & 0.5 & & & $0.1^{d}$ & 0.5 & & & $0.1^{d}$ & 0.7 & & \\
\hline $\begin{array}{l}\text { a The incident hires } \\
\text { b There were } 1300 \\
\text { c Median, IQR for } \\
\text { d Median=0.0, IQR } \\
\text { e Median=0.0, IQR } \\
{ }^{+} \text {Median=0.0, IQR }\end{array}$ & $\begin{array}{l}\text { s subcoh } \\
02 \text { and } 9 \\
1949=19 \\
=0-0 . \\
=0-0.1 . \\
=0-0.3 .\end{array}$ & $\begin{array}{l}\text { 1ort wa } \\
870 \text { dis } \\
40-19\end{array}$ & $\begin{array}{l}\text { s restr } \\
\text { istinct } 0 \\
53 \text {; IQF }\end{array}$ & $\begin{array}{l}\text { ed to wo } \\
\text { itrol sub } \\
\text { or } 1947=\end{array}$ & $\begin{array}{l}\text { rkers wh } \\
\text { jects san } \\
1934-19\end{array}$ & $\begin{array}{l}10 \text { wer } \\
\text { npled } \\
953 ; \text { IC }\end{array}$ & $\begin{array}{l}\text { e hired } 0 \\
\text { from the } \\
\text { QR for } 1\end{array}$ & $\begin{array}{l}\text { or aft } \\
\text { full coh } \\
52 \text { (cas }\end{array}$ & $\begin{array}{l}1 \text { Janua } \\
\text { t and st } \\
\text { ) }=1948\end{array}$ & $\begin{array}{l}19 \\
\text { set } \\
1955\end{array}$ & $\begin{array}{l}\text { incid } \\
\text { IQR }\end{array}$ & $\begin{array}{l}\text { th hir } \\
195\end{array}$ & $\begin{array}{l}\text { spective } \\
\text { ntrols) }=\end{array}$ & $7-1$ & & \\
\hline
\end{tabular}


Table 2. Adjusted mortality rate ratios (MRR) a for lung cancer as function of cumulative exposure to synthetic metalworking fluid (MWF) and years exposed to biocide as estimated by Cox regression nested in the incident hires subcohort of workers hired on or after start of follow-up. [ $95 \% \mathrm{Cl}=95 \%$ confidence interval.]

\begin{tabular}{|c|c|c|c|}
\hline & $\begin{array}{l}\text { Deaths } \\
\text { (N) }\end{array}$ & MRR & $95 \% \mathrm{Cl}$ \\
\hline \multicolumn{4}{|c|}{ Synthetic MWF (mg/m ${ }^{3}$ per year) b } \\
\hline Unexposed & 583 & 1.00 & .. \\
\hline $0-0.27$ & 63 & 0.92 & $0.68-1.24$ \\
\hline$>0.27-0.85$ & 64 & 1.14 & $0.84-1.54$ \\
\hline$>0.85-2.15$ & 63 & 0.85 & $0.62-1.16$ \\
\hline$>2.15$ & 64 & 0.79 & $0.59-1.05$ \\
\hline \multicolumn{4}{|c|}{$\begin{array}{l}\text { Biocide (years exposed with synthetic } \\
\text { MWF) }{ }^{b}\end{array}$} \\
\hline Unexposed & 611 & 1.00 & .. \\
\hline $0-0.13$ & 56 & 1.07 & $0.79-1.46$ \\
\hline$>0.13-0.40$ & 57 & 1.17 & $0.85-1.59$ \\
\hline$>0.40-1.04$ & 56 & 0.94 & $0.69-1.30$ \\
\hline$>1.04$ & 57 & 1.00 & $0.75-1.35$ \\
\hline \multicolumn{4}{|c|}{ Biocide (years exposed with soluble MWF) c } \\
\hline Unexposed & 805 & 1.00 & .. \\
\hline $0-0.66$ & 8 & 0.67 & $0.33-1.38$ \\
\hline$>0.66-1.67$ & 8 & 1.01 & $0.49-2.10$ \\
\hline$>1.67-2.36$ & 8 & 1.70 & $0.81-3.55$ \\
\hline$>2.36$ & 8 & 0.62 & $0.30-1.28$ \\
\hline
\end{tabular}

a Synthetic MWF, biocide with synthetic MWF, and biocide with soluble MWF were fit in separate models; all models were adjusted for straight MWF, race, gender, plant, calendar year, and years since retirement.

${ }^{\mathrm{b}}$ Additional adjustments in model for soluble MWF

${ }^{\mathrm{c}}$ Additional adjustments in model for synthetic MWF

for the MRR and 95\% confidence bands for synthetic MWF from the two models were very similar, but estimates were lower for the full cohort. Within the subcohort, the MRR decreased to 0.63 (95\% CI 0.39-0.98) before turning upward above the $99^{\text {th }}$ percentile $(15.8$ $\mathrm{mg} / \mathrm{m}^{3}$ per year); at the same value for cumulative exposure, the MRR for synthetic MWF decreased to 0.59 (95\% CI 0.36-0.94) in the full cohort. Exclusion of observations in the top percentile of exposure to synthetic MWF did not result in a meaningful difference in the exposure-response (data not shown). Null associations were observed for soluble and straight MWF in all models (data not shown).

Figures $2 \mathrm{a}$ and $2 \mathrm{~b}$ summarize the penalized spline models for years exposed to biocide with both synthetic and soluble MWF, respectively. Linear inverse exposure-response relations were observed for both biocide variables in the incident hires subcohort and the full cohort, but the $95 \%$ confidence bands overlapped the null. MRR estimates were slightly lower in the full cohort compared to the subcohort. All further analysis was restricted to the case-control sample nested in the incident hires subcohort.

Cumulative exposure to synthetic MWF was partitioned into two time windows of exposure (table 3). A significant linear inverse association was observed for the more recent exposure to synthetic MWF. In contrast, a positive exposure-response was observed for synthetic MWF in the earlier time window. Because of the contrast in association between early and recent time windows of exposure, we evaluated effect modification by presence of early synthetic exposure on the association between recent exposure to synthetic MWF and lung cancer mortality; the interaction term was not statistically significant $(\mathrm{P}=0.42)$.

The effect of cumulative exposure to synthetic MWF on lung cancer was also stratified by "ever or never exposed" to biocide in synthetic MWF (figure 3, table 3). A significant linear inverse association was observed for workers simultaneously exposed to synthetic MWF and biocide. In contrast, the MRR increased linearly for those never exposed to biocide, but the $95 \%$ confidence bands overlapped the null across the full range of the exposure distribution. In a single pooled model, the interaction term between cumulative exposure to synthetic MWF and history of exposure to biocide was marginally significant $(\mathrm{P}=0.07)$.

Models for lung cancer as a function of cumulative exposure to synthetic MWF were compared between the previous and extended follow-up periods for the incident hires subcohort (table 4). In the previous follow-up, all of the MRR estimates were below the null and there was an inverse trend across increasing exposure categories (Chi-square test for trend $\mathrm{P}=0.01$ ), consistent with Schroeder et al (27). By contrast, in the extended followup period, the MRR were elevated (with wide $95 \% \mathrm{CI}$ ) in all but the highest quartile of exposure; the Chi-square test for trend was not statistically significant $(\mathrm{P}=0.72)$.

\section{Discussion}

In this updated cohort of autoworkers exposed to MWF, we observed a significant inverse exposure-response relationship between lung cancer mortality and cumulative exposure to synthetic MWF over the entire followup period. The results were very similar between the case-control samples nested in the incident hires subcohort and the full cohort, although MRR estimates were slightly closer to the null among subjects hired after start of follow-up. Compared to cumulative exposure to synthetic MWF, years exposed to biocide in either synthetic or soluble MWF was not strongly protective.

The protective effect of synthetic MWF was observed for recent exposure but not for exposures that occurred $>20$ years prior to risk age. This finding is also consistent with the previous study of lung cancer and MWF, and with the increasing use of biocides over calendar time. It also raises the question of whether any protection following exposure to endotoxin is sustained 
- - - - Full cohort

$95 \%$ confidence bands
Incident hires subcohort

$95 \%$ confidence bands

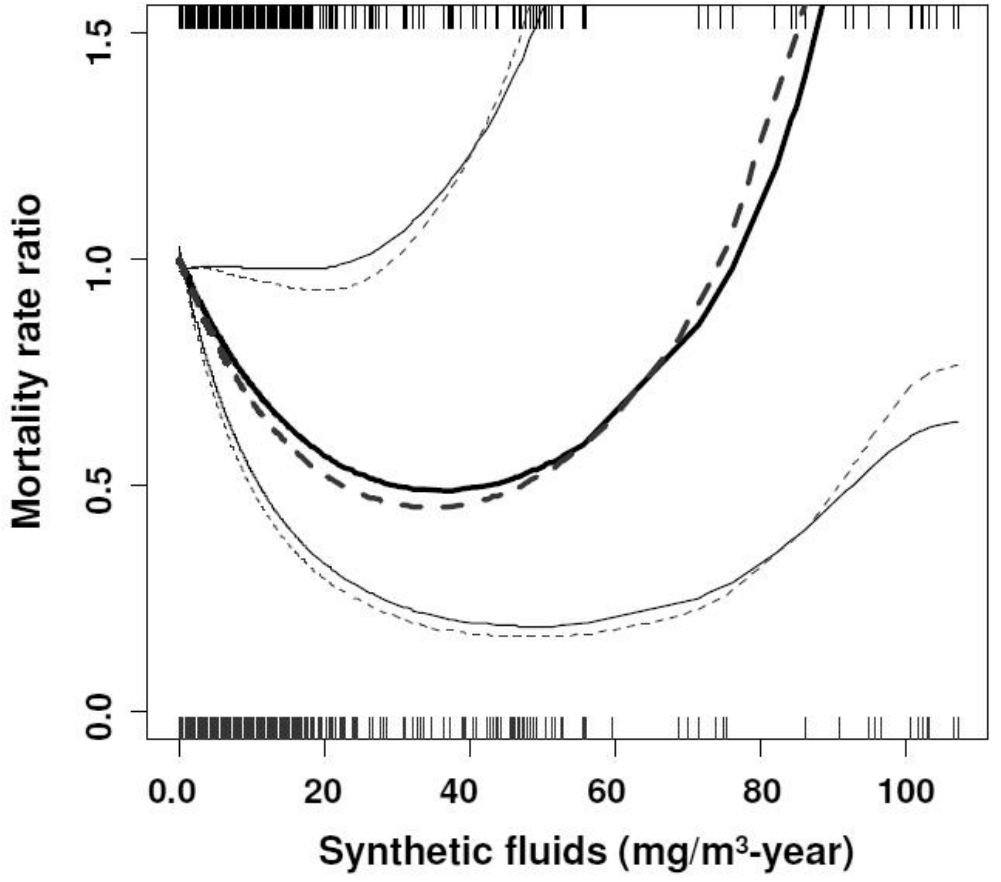

Figure 1. Adjusted mortality rate ratios (MRR) of lung cancer as a function of cumulative exposure to synthetic metalworking fluid (MWF) as estimated by Cox regression using penalized splines in the full cohort and subcohort, the latter of which is restricted to workers hired on or after start of follow-up. Models adjusted for straight and soluble MWF $\left(\mathrm{mg} / \mathrm{m}^{3}\right.$ per year), gender, race, plant, calendar year, and years since retirement. Straight, soluble, and synthetic MWF, calendar year, and years since retirement were treated as non-linear terms if Akaike information criterion (AIC) selected degrees of freedom $>1.0$ and $P<0.10$. Rug plots represent the distribution of exposure for subcohort (top) and the full cohort (bottom) $\ldots-\ldots$ Full cohort
$95 \%$ confidence bands

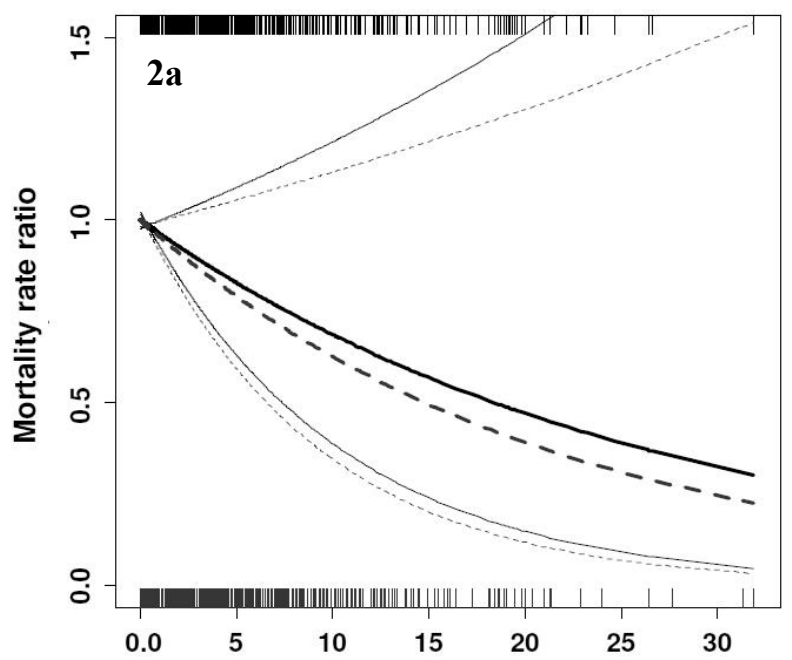

Years exposed to biocide with synthetic fluids

\author{
Incident hires subcohort \\ $95 \%$ confidence bands
}

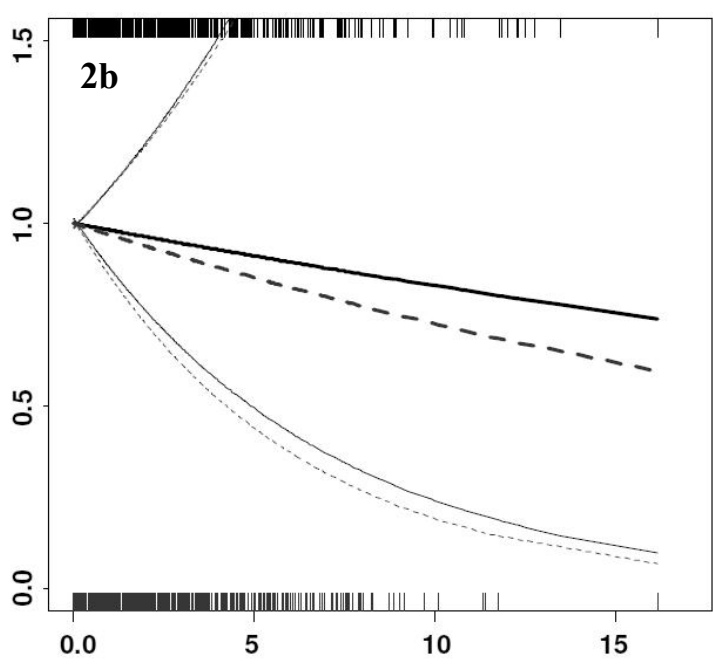

Years exposed to biocide with soluble fluids

Figures $\mathbf{2 a} \mathbf{a} \mathbf{2 b}$. Adjusted mortality rate ratios (MRR) of lung cancer as a function years exposed to biocide with synthetic metalworking fluid (MWF) (2a) and with soluble MWF (2b) as estimated by Cox regression using penalized splines in the full cohort and subcohort. The subcohort is restricted to workers hired on or after start of follow-up. All models were adjusted for straight MWF ( $\mathrm{mg} / \mathrm{m}^{3}$ per year), soluble MWF ( $\mathrm{mg} / \mathrm{m}^{3}$ per year) (only in $2 \mathrm{a}$ ), synthetic MWF ( $\mathrm{mg} / \mathrm{m}^{3}$ per year) (only in $2 \mathrm{~b}$ ), race, gender, plant, calendar year, and years since retirement. Years exposed to biocide with synthetic and soluble MWF, straight MWF, soluble MWF, synthetic MWF, calendar year, and years since retirement were treated as non-linear terms if degrees of freedom selected by Akaike information criterion $(A I C)>1.0$ and if $P<0.10$. Rug plots represent the distribution of exposure for incident hires (top) and the full cohort (bottom). 
- - - Exposed to biocide $95 \%$ confidence bands
Never exposed to biocide $95 \%$ confidence bands

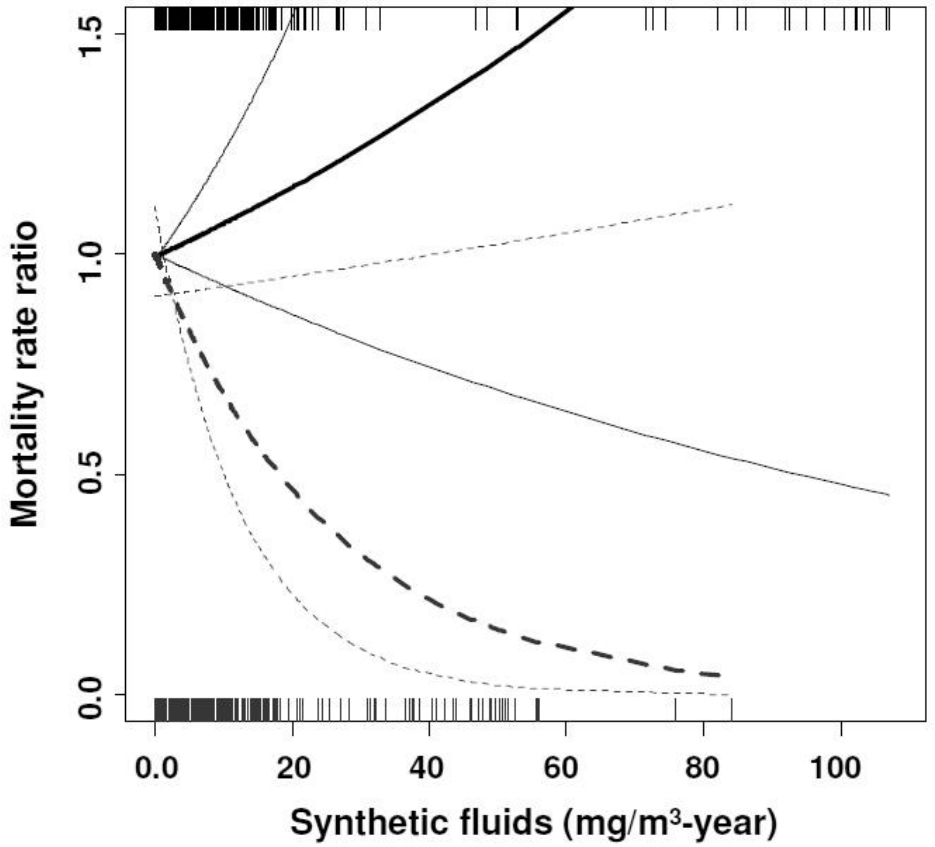

Figure 3. Adjusted mortality rate ratios (MRR) of lung cancer as a function of synthetic metalworking fluid (MWF) after stratification by history of exposure to biocide (in synthetic MWF) as estimated by Cox regression using penalized splines in the incident hires subcohort of workers hires on or after start of follow-up. Models were adjusted for straight and soluble MWF ( $\mathrm{mg} / \mathrm{m}^{3}$ per year), race, gender, plant, calendar year, and years since retirement. Straight, soluble and synthetic MWF, calendar year, and years since retirement were treated as non-linear terms if degrees of freedom were selected by Akaike information criterion (AIC) $>1.0$ and if $P<0.10$. Rug plots represent the distribution of exposure to synthetic MWF among workers never exposed (top) and ever exposed (bottom) to biocide.

Table 3. Adjusted mortality rate ratios (MRR) a for lung cancer mortality in the subcohort of workers hired on or after start of follow-up predicted from Cox regression models using penalized splines in this study. [MWF=metalworking fluid; $95 \% \mathrm{Cl}=95 \%$ confidence interval; $\mathrm{N} / \mathrm{A}=$ not available.]

\begin{tabular}{|c|c|c|c|c|c|c|c|c|c|c|c|c|}
\hline \multirow[t]{2}{*}{ Percentile } & \multicolumn{3}{|c|}{$\begin{array}{l}\text { Early exposure to synthetic } \\
\text { MWF (>20 years) }\end{array}$} & \multicolumn{3}{|c|}{$\begin{array}{l}\text { Recent exposure to synthetic } \\
\text { MWF ( } \leq 20 \text { years })^{b}\end{array}$} & \multicolumn{3}{|c|}{$\begin{array}{l}\text { Synthetic MWF with } \\
\text { biocide }{ }^{b, c}\end{array}$} & \multicolumn{3}{|c|}{$\begin{array}{l}\text { Synthetic MWF without } \\
\text { biocide } b, c\end{array}$} \\
\hline & $\begin{array}{c}\mathrm{mg} / \mathrm{m}^{3} \text { per } \\
\text { year }\end{array}$ & MRR & $95 \% \mathrm{Cl}$ & $\begin{array}{c}\mathrm{mg} / \mathrm{m}^{3} \text { per } \\
\text { year }\end{array}$ & MRR & $95 \% \mathrm{Cl}$ & $\begin{array}{c}\mathrm{mg} / \mathrm{m}^{3} \text { per } \\
\text { year }\end{array}$ & MRR & $95 \% \mathrm{Cl}$ & $\begin{array}{l}\mathrm{mg} / \mathrm{m}^{3} \text { per } \\
\text { year }\end{array}$ & MRR & $95 \% \mathrm{Cl}$ \\
\hline $25^{\text {th }}$ & 0 & $\mathrm{~N} / \mathrm{A}$ & .. & 0 & $\mathrm{~N} / \mathrm{A}$ &.. & 0.24 & 0.99 & $0.90-1.09$ & 0 & $N / A$ & .. \\
\hline $50^{\text {th }}$ & 0 & $\mathrm{~N} / \mathrm{A}$ & .. & 0 & $\mathrm{~N} / \mathrm{A}$ & .. & 0.98 & 0.96 & $0.91-1.02$ & 0 & $\mathrm{~N} / \mathrm{A}$ & .. \\
\hline $75^{\text {th }}$ & 0.03 & 1.00 & $0.99-1.02$ & 0 & $\mathrm{~N} / \mathrm{A}$ & .. & 2.26 & 0.92 & $0.91-0.93$ & 0 & $N / A$ &.. \\
\hline $90^{\text {th }}$ & 1.46 & 1.02 & $1.01-1.03$ & 0.62 & 0.93 & $0.90-0.95$ & 5.33 & 0.82 & $0.73-0.92$ & 0 & N/A & .. \\
\hline $99^{\text {th }}$ & 14.18 & 1.27 & $0.97-1.66$ & 8.62 & 0.34 & $0.14-0.81$ & 37.48 & 0.24 & $0.06-0.99$ & 11.60 & 1.08 & $0.92-1.28$ \\
\hline
\end{tabular}

a Cox models were adjusted for straight MWF ( $\mathrm{mg} / \mathrm{m}^{3}$ per year), soluble MWF $\left(\mathrm{mg} / \mathrm{m}^{3}\right.$ per year), race, gender, plant, calendar year, and years since retirement. ${ }^{b}$ Synthetic MWF in all models was treated as a linear term, but soluble MWF, straight MWF, calendar year, and years since retirement were treated as non-linear terms if degrees of freedom selected by Akaike information criterion (AIC) exceeded 1.0 and if $P<0.10$.

c Predicted MRR of synthetic MWF derived from models presented in Figure 3.

Table 4. Adjusted mortality rate ratios (MRR) a for lung cancer as function of cumulative exposure to synthetic metalworking fluid (MWF) as estimated by Cox regression nested in the incident hires subcohort of workers hired on or after start of follow-up during the early and extended follow-up periods. [95\% $\mathrm{Cl}=95 \%$ confidence intervals.]

\begin{tabular}{|c|c|c|c|c|c|c|}
\hline \multirow[t]{2}{*}{ Synthetic MWF (mg/m³ per year) ${ }^{b}$} & \multicolumn{3}{|c|}{ Previous follow-up (1941-1984) } & \multicolumn{3}{|c|}{ Extended follow-up (1985-1994) } \\
\hline & $\mathrm{N}$ deaths & MRR & $95 \% \mathrm{Cl}$ & $\mathrm{N}$ deaths & MRR & $95 \% \mathrm{Cl}$ \\
\hline Unexposed & 309 & 1.00 & .. & 274 & 1.00 & .. \\
\hline $0-0.23,0-0.28$ & 26 & 0.73 & $0.49-1.15$ & 37 & 1.10 & $0.73-1.67$ \\
\hline$>0.23-0.84,0.28-0.88$ & 27 & 0.78 & $0.49-1.23$ & 37 & 1.29 & $0.85-1.96$ \\
\hline$>0.84-1.93,0.88-2.28$ & 26 & 0.70 & $0.44-1.12$ & 37 & 1.23 & $0.81-1.86$ \\
\hline$>1.93,>2.28$ & 27 & 0.45 & $0.29-0.71$ & 37 & 0.97 & $0.66-1.43$ \\
\hline
\end{tabular}

a Cox models were adjusted for straight MWF, soluble MWF, race, gender, plant, calendar year, and years since retirement.

${ }^{b}$ Exposure cut-offs for increasing quartile of cumulative exposure to total mass particulate metalworking fluid ( $\mathrm{mg} / \mathrm{m}^{3}$ per year) determined by distribution of exposed cases; first and second exposure intervals listed reflect previous and extended follow-up periods, respectively. 
following cessation of exposure. A study from the dairy farming industry observed that the risk of lung cancer mortality was greater among farmers who retired $\geq 15$ years prior to end of follow-up than those who retired more recently (7).

We also observed opposite effects of synthetic MWF on lung cancer mortality among subjects, unadjusted for coexposure to biocide, although the confidence bands were wide due to smaller numbers of biocideexposed workers. The results are difficult to explain in the absence of directly measured endotoxin. Endotoxin exposure data collected in other work environments with MWF have become available only recently. It may be that endotoxin per se does not explain the observed findings. It is also possible that the protective effect of synthetic MWF depends on the specific time window of biocide application, which is unknown. There are no existing studies with direct measurements of both endotoxin and biocide in a work environment with MWF. A 1-year study monitoring microbial growth in bulk samples found that replacing a used (and contaminated) synthetic MWF sump system with a fresh one containing biocides killed most of the remaining bacteria, but that within a few weeks, the surviving bacteria had multiplied to levels even higher than those before replacement (24). A six-month study that monitored bacterial counts in bulk samples of semi-synthetic MWF before and after treatment of biocide observed a decrease followed by an increase in bacterial counts 1 and 3 months after treatment, respectively (25). Another study that evaluated the use of biocide in water-based MWF observed a sharp increase in endotoxin and bacterial concentration when biocide application was not sustained at a high concentration (26). Collectively these studies suggest that careful management of biocide application may be critical in maintaining targeted levels of endotoxin.

These results generally support the previous finding of a protective association for synthetic MWF and lung cancer in this cohort. When we estimated a single hazard ratio over the entire follow-up period, we observed a significant inverse association between synthetic fluids and lung cancer over a wider range of exposure estimates. Although we expected the MRR estimates to be inverse with narrower confidence bands, we found that the MRR were slightly closer to the null. In fact, when stratified by follow-up period, the effect of synthetic fluids on lung cancer was no longer inverse during the more recent follow-up period. There are several possible explanations for this attenuated effect. First, it may be that the observed inverse effect in the early follow-up period was due to chance. Second, an unmeasured constituent of synthetic MWF that contributed to the inverse effect may have been eliminated from the formulation of synthetic MWF in most recent years. Third, changes in unmeasured cigarette smoking might have occurred over time (discussed further below as a limitation). The most likely explanation for the change in MRR over time, however, may be the built-in selection bias of the hazard ratio, as recently described by Hernán (33). Selection bias may be induced by inclusion of survivors from the previous follow-up period due to depletion of participants most susceptible to the protective effects (least likely to have died of lung cancer). Thus subjects who survived until 1985 are more likely to die of lung cancer, although the excess would be unrelated to exposure.

There has been an accumulation of evidence from occupational epidemiologic studies in recent years suggesting a protective effect of endotoxin on lung cancer, specifically in the cotton textile and farming industries $(12,15)$. However, the anti-tumorgenic mechanisms of endotoxin are not well understood, but they may be a product of complex interactions between the innate and adaptive immune responses linked by toll-like receptors (TLR) (13). TLR4 in particular is the receptor to which bacterial endotoxin LPS binds in conjunction with protein molecules CD14 and MD2. The binding of LPS to this CD14-TLR4-MD2 complex leads to a series of signal transduction events where the alveolar macrophages are activated, leading to the production and release of proinflammatory cytokines, chemokines, adhesion molecules, and other nonspecific inflammatory mediators $(34,35)$. Whether the innate immune response related to TLR4 triggers adaptive immunity that may inhibit lung tumor growth remains to be addressed. For example, other TLR, particularly TLR7 and TLR9, are known to initiate a helper T-cell (Th1) immune response that promotes upregulation of cancer-killing T-cells and pro-inflammatory mediators inhibiting tumor growth through tumor antigen recognition (13). Furthermore, the potential protective effect of occupational endotoxin exposure on lung cancer is more relevant in understanding the etiology of the disease, perhaps with respect to developing antitumorgenic therapeutics, rather than influencing the proposed NOEL for various non-malignant respiratory health endpoints.

An inherent limitation of our study is that endotoxin exposure was not measured directly and that surrogates for this exposure (ie, synthetic MWF and biocide) were used. There is evidence, however, to suggest that airborne endotoxin and total particulate mass to waterbased MWF are positively correlated (18-20). The UAW-GM study is the only existing cohort study with quantitative exposure estimates for MWF. A more extensive exposure assessment study of MWF in auto manufacturing is needed to assess bacterial identification, and endotoxin concentration measured in air and bulk samples. Quantitative measurement of specific biocides could provide estimates of exposure to endotoxin in this and other occupational cohorts with exposure to MWF.

Another inherent limitation is unmeasured confounding. Smoking is a strong risk factor for lung cancer and 
it may be more common in the unexposed, although there is no reason to suppose that is the case. A crosssectional study of a subset of this population reported a higher prevalence of "ever smokers" among machinists exposed to synthetic MWF than assembly workers not exposed to MWF $(75.7 \%$ versus $69.5 \%$, respectively) (36). A recent review of the role of confounding in occupational studies of well-established carcinogens also suggests that confounding by tobacco use in studies of lung cancer is not likely to explain positive study findings (37). However, it is possible that small differences in smoking patterns may confound the exposure-response, particularly above the $99^{\text {th }}$ percentile of exposure where there were few cases.

Inverse associations observed for synthetic MWF in this study may be explained by downward bias from the healthy worker survival effect. That is, if the true association between endotoxin and lung cancer is null, then the healthy worker effect may explain the inverse association observed here (38). We attempted to reduce this effect bias by restricting the nested case-control analysis to incident hires who were hired on or after the start of follow-up (ie, excluding the prevalent hires, who are considered survivors hired before baseline), and by adjusting for years since retirement. As described by Applebaum et al (31), prevalent hires may not be representative of all workers hired at the same time because they were able to continue to work until the start of follow-up. Bias may be compounded if both the healthy worker survival effect and prevalent hires are present (31). Exclusion of prevalent hires in this analysis, however, did not change our findings for synthetic MWF and lung cancer. This may be because of the relatively recent widespread use of synthetic MWF in auto manufacturing and the fact that the majority of the study population was hired after the start of follow-up in 1941.

In summary, a non-linear exposure-response identified significant inverse risk of lung cancer for workers with high exposure to synthetic MWF, but the protective effect was observed only for those with co-exposure to biocide. Additional exposure validation for endotoxin is necessary in order to evaluate the risk of lung cancer mortality in relation to endotoxin exposure in the auto manufacturing industry.

\section{Acknowledgements}

This study received funding from the National Cancer Institute at the National Institutes of Health [NCI CA74386] and the National Institute for Occupational Safety and Health at the Centers for Disease Control and Prevention [R01 OH02421], [K01 OH009390], and
[T42OH008416]. The authors would like to acknowledge the contribution of Rebecca Gore, University of Massachusetts Lowell, and Erika Garcia, University of California Berkeley School of Public Health, for their assistance with data management.

\section{References}

1. Todar K. Bacterial endotoxin. Todar's Online Textbook of Bacteriology. 2008. Available at: http://textbookofbacteriology. net/endotoxin.html.

2. Milton D. K. Endotoxin and Other Bacterial Cell-Wall Components. In: Macher J, editors. Bioaerosols: Assessment and Control. Cincinnati, OH: ACGIH; 1999. Chapter 23.

3. Thelin A, Tegler O, Rylander R. Lung reactions during poultry handling related to dust and bacterial endotoxin levels. Eur J Respir Dis. 1984;65:266-71.

4. Rylander R, Bake B, Fischer JJ, Helander IM. Pulmonary function and symptoms after inhalation of endotoxin. Am Rev Respir Dis. 1989;140:981-986.

5. Schwartz DA, Thorne PS, Jagielo PJ, White GE, Bleuer SA, Frees KL. Endotoxin responsiveness and grain dust-induced inflammation in the lower respiratory tract. Am J Physiol. 1994;267:L609-17.

6. Christiani DC, Wang XR, Pan LD, Zhang HX, Sun BX, Dai $\mathrm{H}$, et al. Longitudinal changes in pulmonary function and respiratory symptoms in cotton textile workers: a 15- yr followup study. Am J Respir Crit Care Med. 2001;163:847-853.

7. Mastrangelo G, Grange JM, Fadda E, Fedeli U, Buja A, Lange JH. Lung cancer risk: effect of dairy farming and the consequence of removing that occupational exposure. AmJ Epidemiol. 2005;161:1037-46.

8. Daum, SM, Seidman H, Heimann H, Richter E, Selikoff IJ Mortality experience of a cohort of cotton textile workers. Final progress report on Contract No. HSM 99-72-71. (NIOSH). Department of Health and Human Services: Washington, DC; 1975.

9. Merchant JA, Ortmeyer C. Mortality of employees of two cotton mills in North Carolina. Chest. 1981;79:6S-11S.

10. Hodgson JT, Jones RD. Mortality of workers in the British cotton industry in 1968-1984. Scand J Work Environ Health. 1990;16:113-20.

11. Astrakianakis G, Seixas NS, Ray R, Camp JE, Gao DL, Feng $\mathrm{Z}$, Li W, et al. Lung cancer risk among female textile workers exposed to endotoxin. J Natl Cancer Inst. 2007; 99:357-64.

12. Lenters V, Basinas I, Beane-Freeman L, Boffetta P, Checkoway $\mathrm{H}$, Coggon D, et al. Endotoxin exposure and lung cancer risk: a systematic review and meta-analysis of the published literature on agriculture and cotton textile workers. Cancer Causes Control 2010;21:523-55.

13. Schmidt C. Immune system's Toll-like receptors have good opportunity for cancer treatment. J Natl Cancer Inst. 2006;98:574-5. 
14. Lange JH, Mastrangelo G, Buja A. Occupational exposure to endotoxin reduces lung cancer rates. Occup Med (Lond). 2005;55:154-5.

15. Lundin JI, Checkoway H. Endotoxin and cancer. Environ Health Perspect. 2009; 117:1344-50.

16. Eisen EA, Bardin J, Gore R, Woskie SR, Hallock MF, Monson RR. Exposure response models based on extended follow-up of a cohort mortality study in the automobile industry. Scand J Work Environ Health. 2001;27:240-9.

17. Buers KLM, Prince EL, Knowles CJ. The ability of selected bacterial isolates to utilise components of synthetic metalworking fluids as sole sources of carbon and nitrogen for growth. Biotechnology Letters. 1997;19:791-794.

18. Thorne PS, DeKoster JA, Subramanian P. Environmental assessment of aerosols, bioaerosols, and airborne endotoxins in a machining plant. AIHAJ. 1996;57:1163-1167.

19. Abrams L, Seixas N, Robins T, Burge H, Muilenberg M, Franzblau A. Characterization of metalworking fluid exposure indices for a study of acute respiratory effects. Appl Occup Environ Hyg. 2000;15:492-502.

20. Woskie SR, Virji MA, Hallock M, Smith TJ, Hammond SK. Summary of the findings from the exposure assessments for metalworking fluid mortality and morbidity studies. Appl Occup Environ Hyg. 2003;18:855-64.

21. Wang H, Reponen T, Lee SA, White E, Grinshpun SA. Size distribution of airborne mist and endotoxin-containing particles in metalworking fluid environments. J Occup Environ Hyg. 2007;4:157-65.

22. Heederik D, Douwes J. Towards an occupational exposure limit for endotoxins? Ann Agric Environ Med. 1997;4:17-19.

23. Douwes J, Thorne P, Pearce N, Heederik D. Bioaerosol health effects and exposure assessment: progress and prospects. Ann Occup Hyg. 2003;47:187-200.

24. Mattsby-Baltzer I, Sandin M, Ahlström B, Allenmark S, Edebo M, Falsen E, et al. Microbial growth and accumulation in industrial metal-working fluids. Appl Environ Microbiol. 1989;55:2681-9.

25. Veillette M, Thorne PS, Gordon T, Duchaine C. Six month tracking of microbial growth in a metalworking fluid after system cleaning and recharging. Ann Occup Hyg. 2004;48:541-6.

26. Linnainmaa M, Kiviranta $\mathrm{H}$, Laitinen J, Laitinen S. Control of workers' exposure to airborne endotoxins and formaldehyde during the use of metalworking fluids. AIHA J. 2003;64:496-500.
27. Schroeder JC, Tolbert PE, Eisen EA, Monson RR, Hallock MF, Smith TJ, et al. Mortality studies of machining fluid exposure in the automobile industry. IV: A case-control study of lung cancer. Am J Ind Med. 1997;31:525-33.

28. Eisen EA, Tolbert PE, Monson RR, Smith TJ. Mortality studies of machining fluid exposure in the automobile industry I: A standardized mortality ratio analysis. Am J Ind Med. 1992;22:809-24.

29. Hallock MF, Smith TJ, Woskie SR, Hammond SK. Estimation of historical exposures to machining fluids in the automotive industry. Am J Ind Med. 1994;26:621-34.

30. Woskie SR, Smith TJ, Hallock MF, Hammond SK, Rosenthal F, Eisen EA, et al. Size-selective pulmonary dose indices for metal-working fluid aerosols in machining and grinding operations in the automobile manufacturing industry. Am Ind Hyg Assoc J. 1994;55:20-9.

31. Applebaum KM, Malloy EJ, Eisen EA. Reducing healthy worker survivor bias by restricting date of hire in a cohort study of Vermont granite workers. Occup Environ Med. 2007;64:681-7.

32. Therneau TM, Grambsch PM. Modeling survival data: extending the Cox model. New York: Springer-Verlag; 2000.

33. Hernán MA. The hazards of hazard ratios. Epidemiology. 2010;21:13-5.

34. LeVan TD, Von Essen S, Romberger DJ, Lambert GP, Martinez FD, Vasquez MM, et al. Polymorphisms in the CD14 gene associated with pulmonary function in farmers. Am J Respir Crit Care Med. 2005;171:773-9.

35. Butchar JP, Parsa KV, Marsh CB, Tridandapani S. Negative regulators of toll-like receptor 4-mediated macrophage inflammatory response. Curr Pharm Des. 2006;12:4143-53.

36. Greaves IA, Eisen EA, Smith TJ, Pothier LJ, Kriebel D, Woskie SR, et al. Respiratory health of automobile workers exposed to metal-working fluid aerosols: respiratory symptoms. Am J Ind Med. 1997;32:450-9.

37. Blair A, Stewart P, Lubin JH, Forastiere F. Methodological issues regarding confounding and exposure misclassification in epidemiological studies of occupational exposures. Am J Ind Med. 2007;50:199-207.

38. Richardson D, Wing S, Steenland K, McKelvey W. Timerelated aspects of the healthy worker survivor effect. Ann Epidemiol. 2004;14:633-9.

Received for publication: 31 March 2010 